\title{
Biomecânica do Desporto - estado da arte na FCDEF-UP (Elogio do Professor José Ferreira da Silva)
}

\author{
J. Paulo Vilas-Boas
}

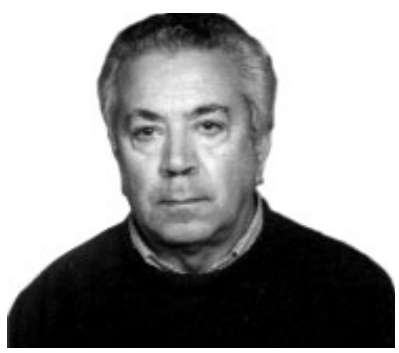

É com subida honra que me encontro aqui hoje entre tão ilustres personalidades, entre os colegas que estimo, na escola que me formou e que me dá sentido como profissional, homenageando personalidades que desde sempre, desde o primeiro contacto, e de há muito, admiro profundamente.

A minha emoção é ainda maior por me ter sido proposto que consubstanciasse este meu humilde contributo para esta sessão com uma intervenção que versasse o estado actual de desenvolvimento da Biomecânica na FCDEF-UP e que, a propósito dele, sublinhasse o contributo indelével que o Professor Ferreira da Silva foi querendo legar a esta instituição. É normalmente com profunda admiração que escuto as palavras sábias das personalidades habituadas a estas circunstâncias e hábeis nestas competências. Admiração que me confronta quase sempre com a consciência angustiada de se me escapar a arte para esses cometimentos. Foi, por isso, com apreensão que recebi esta incumbência dos Professores Jorge Bento e António Marques. Apreensão redobrada por saber que é bem fácil não corresponder às expectativas de alguém que sempre nos habituou a encontrar a palavra certa para o momento certo... a percepção correcta das circunstâncias, das causas e das coisas... o adjectivo certo para qualificar uma personalidade, uma obra e um percurso e para fazer sobrelevar do seu discurso os sublinhados necessários para que cresçam as obras, os desígnios e as emoções. Fiquei, portanto, bem mais tranquilo quando percebi que o que me era pedido passava tão simplesmente por traçar o percurso e o retrato de hoje da Biomecânica na minha Faculdade, decorrência maior da tangência do Professor Ferreira da Silva com esta instituição, mas também parte da minha história, elemento nuclear do meu quotidiano e, sobretudo, uma das grandes paixões da minha carreira.

De facto, é um privilégio de muito poucos fazer quotidianamente aquilo de que mais se gosta e ainda ser pago para isso. Mas constitui, porventura, sorte maior, ser chamado a executar uma tarefa complexa como é a de homenagear figuras tão queridas e ilustres através, exactamente, de uma revisitação do percurso das nossas paixões, das nossas emoções, das nossas convicções, dos nossos esforços, dos nossos pequenos êxitos, dos nossos inêxitos e das nossas angústias. É claro que isto só é possível, porque o Professor Ferreira da Silva foi sendo, ao longo dos últimos 15 anos, a pedra angular da evolução que conseguimos, mesmo se foi exercitando a sua influência e evidenciando a sua competência de forma discreta, suave, quase paternal, exemplo absoluto da mão segura do mestre que sabe orientar os seus discípulos sem os constranger e proporcionando-lhes até a ilusão de um certo protagonismo no seu próprio amadurecimento.

Senhor Professor Ferreira da Silva: permita-me, que revisite o nosso passado comum sem ser tolhido pelo medo da inconfidência, antes deixando fluir as lembranças à medida das conveniências, por forma a tornar evidente para quem acompanhou este percurso - o da nossa Biomecânica - de menos perto, a medida real da sua influência e protagonismo, antes de passar mais objectivamente ao esboço do seu perfil actual.

A presença efectiva do Professor Ferreira da Silva na nossa Faculdade tem aproximadamente o mesmo tempo que a minha docência na casa. Pude, por isso, conhecê-la "on line" e coube-me a sorte de a ter podido pesar melhor, por ter querido o destino, o próprio 
Professor Ferreira da Silva e também o Professor Jorge Bento, que ela me tangesse de especialmente perto. Esta presença começou, julgo, há quase 20 anos, num momento decisivo da nossa história, quando foi necessário impor a mais elementar justiça humana e académica, ressarcindo de profundas injustiças um homem que, depois, logo depois, se veio a mostrar como um dos esteios fundamentais da construção de tudo quanto, hoje, nesta casa, nos rodeia. Desde então, o Professor Ferreira da Silva não mais deixou de nos acarinhar, não mais nos privou do seu sábio conselho, da sua afável companhia e, sobretudo, da sua solidariedade e do seu afecto. A sua presença inicial ganhou visibilidade maior, talvez, pelo papel decisivo que desempenhou, em parceria com o Professor Nuno Grande, outro nome ilustre da nossa Universidade, no então embrionário Conselho Científico desta escola.

Foi pouco depois que, pela mão do Professor Jorge Olímpio Bento, tive o privilégio de o conhecer, quando decidi que levaria a minha carreira académica pelo rumo da Biofísica. Recebeu-me então no seu velho Laboratório dos Leões, onde fui confrontado com a expressão material das noções de ORDEM, DESORDEM e ORGANIZAÇÃO. Foi uma das minhas primeiras lições práticas acerca da teoria dos sistemas, depois do fascínio das leituras de Morin, Rosnay, Jacob, ou Labourit, que outros de muito boa lembrança me haviam proporcionado na licenciatura. Mas, verdadeiramente fascinante foi perceber que o Professor Ferreira da Silva conseguia mergulhar um braço até à axila num mar de livros e dossiers que inundavam aquele espaço, nos rolos de papel milimétrico e papers de supercondutividade, e, como que por magia, fazia emergir uma qualquer minudência relevante para o nosso encontro: um escrito meu, por exemplo, muito elogiado, mas profundamente anotado, interrogado e corrigido. Percebi melhor, então, as diferenças entre o complexo e o complicado, percebi melhor a relevância e o próprio valor energético, físico, da "informação" e redimensionei as fronteiras do mágico; mas guardei para mim também uma das primeiras angústias do meu convívio com os físicos: a de não ter sido capaz de reconhecer se se tratava de um ambiente de um tipo, ou de outro... se complicado e pouco organizado, se hiperorganizado e complexo. Espero que ainda lhe reste paciência para um dia mo esclarecer.

Nesse tempo, estávamos em 1985, creio, o Senhor Professor, proporcionou-me mais uma das muitas lições de vida que a nossa interacção me prodigalizou. Tratava-me deferentemente por Senhor Doutor; conseguia-me sempre o bem mais precioso: uma cadeira desocupada para me sentar a seu lado no seu Laboratório e, depois, simpaticamente, esclarecia-me de que os meus escritos estavam a anos-luz do mínimo requerido para serem levados a sério. Encomendou-me, então, à biblioteca do Departamento, e prescreveu-me encontros generosos com os seus estudantes de últimos anos para debatermos as coisas da termodinâmica e da mecânica de fluídos. Fez-me estudar! Depois, quando lhe foi dito da minha aparente suficiência, entretanto conquistada, honrou-me com o privilégio de me chamar pelo nome. Deixei de ser "SENHOR DOUTOR" e passei a ser de confiança (digo eu). Passei a ser o "JOÃO PAULO". Depois, passaram-se as provas de Aptidão Pedagógica e de Capacidade Científica e o doutoramento, com o qual se quebrou a magia: o coche voltou a ser abóbora, e passou a tratar-me com um "CARO COLEGA" que, confessolho hoje, me é bem menos querido do que o meu nome próprio na sua boca, porque me faz sentir menos próximo do professor.

Mas esta história é relevante, e trago-a aqui, fundamentalmente para sublinhar que as influências que recebemos, os ensinamentos de que desfrutamos, os estímulos e os impulsos que nos dinamizaram, foram sempre temperados por uma incontornável vocação educativa, repleta de valores que preenchem hoje a minha consciência de professor, de tutor e de coordenador de recursos humanos. E o maior deles é, porventura, a confiança. A confiança onde se escoram a solidariedade e a cumplicidade e que só frutifi$\mathrm{ca}$, de facto, entre as pessoas de bem.

Durante este percurso foi-se, entretanto, fazendo Biomecânica na Faculdade, ajudando a crescer a Biomecânica da FCDEF-UP. Crescimento a que o Professor Ferreira da Silva esteve sempre ligado, umas vezes mais explicitamente, outras, naturalmente menos, mais subtilmente, desde logo através dos produtos que foi formando: os seus discípulos. E foi bastante o que se fez! Foi grande o crescimento que se operou, a partir de uma simples disciplina de 
licenciatura, corajosamente escorada em dois ou três volumes de uma biblioteca insipiente, pelo seu precursor, que hoje aqui não podemos deixar de lembrar: o Professor José Luís de Castro Gonçalves. Pediram-me, Professor Ferreira da Silva, que traçasse aqui o percurso desta evolução e que definisse o estado actual desse desenvolvimento. E pediram-me que o fizesse em tom de homenagem ao Professor. Não haveria opção melhor, já que esta evolução, e o respectivo estado actual, conformam a influência decisiva que o Professor teve em todos nós, seja como instituição, seja como pessoas. Permitam-me, portanto, que trace esse percurso e que retrate o presente, sem o cuidado de enfatizar os contributos particulares do Professor Ferreira da Silva.

Assumamos desde já que, por detrás de cada conquista, amparando cada passo, cada hesitação, ou sustentando cada atrevimento, estava sempre a mão segura e a personalidade avisada do Professor Ferreira da Silva.

No início deste percurso evolutivo que nos propomos analisar (relembremos que nos projectámos há uns quase vinte anos atrás), dispúnhamos de uma disciplina de licenciatura tida como "um cadeirão", bem organizada e exigente, com uma taxa de sucesso escolar pouco lisonjeira que, por isso, diga-se, não ajudava um docente, mesmo que dedicado e corajoso, a fazer escola. Caricata, ou caricaturalmente, dispúnhamos também de um dinamómetro de mola para a avaliação da força de preensão, de uma tabuleiro de quadrícula posturográfica e de um espirómetro portátil, que não se sabia bem o que fazia entre os equipamentos de Biomecânica. Em suma, vertiam-se os conceitos possíveis com a convicção possível, sem o determinante sustentáculo da vivência e da experiência laboratoriais.

Congregaram-se, então, um conjunto de circunstâncias que ajudariam a mudar o rumo dos acontecimentos. A escola crescia; a investigação tinha de ser implementada; havia que qualificar o pessoal docente; impunha-se que os docentes se doutorassem. Foi neste contexto que surgiu a vontade expressa pelo Professor Castro Gonçalves de realizar o seu doutoramento sob orientação do Professor Luís de Almeida, da Faculdade de Medicina da Universidade do Porto. Ao mesmo tempo, teve início a colaboração directa do Professor Ferreira da Silva na regência e leccionação da disciplina e na orientação de provas académicas de docentes mais jovens, nomeadamente eu próprio. A meu lado, e igualmente fascinado pela relevância termodinâmica da técnica desportiva no contexto mais vasto dos factores determinantes da optimização do rendimento desportivo, militava o verdadeiro precursor da Biomecânica Laboratorial na nossa escola. Aquele que dá hoje o nome ao Laboratório que dirijo: o saudoso Dr. André Costa. Num primeiro tempo, o André, orientado pelo Professor Nuno Grande, entusiasmou-se pelo input energético do sistema biológico, nomeadamente pelos meios de avaliação da faixa de intensidade correspondente ao que comunmente designamos por limiar anaeróbio. Pelo meu lado, fascinava-me a influência da eficiência dos mecanismos propulsivos inerentes à locomoção humana no respectivo custo energético, determinando implicações diversas dos sistemas fornecedores de energia para o trabalho biológico. Ambos, entretanto, decidimos inflectir as nossas preocupações para o estudo das razões biomecânicas subjacentes à maximização do rendimento energético do movimento desportivo, enquanto que o Professor José Luís de Castro Gonçalves se consagrava à Biomecânica interna, valorizando a avaliação do stress determinante de lesões raquideanas típicas dos ginastas (espondiloses e espondilolistésis) recorrendo a modelos físicos naturais com integração de elementos anatómicos simulados, nomeadamente os discos inter-vertebrais e as estruturas músculo-tendinosas e ligamentares.

Este foi o período dos primeiros ensaios de avaliação cinemática na FCDEF-UP, fosse através da avaliação radiológica da mobilidade vertebral desenvolvida pelo Professor José Luís de Castro Gonçalves em 1990, fosse através do recurso ao registo do traçado luminoso contínuo e intermitente para a avaliação, quer da cinemática segmentar (trajectórias e amplitudes), quer das flutuações intracíclicas da velocidade de um ponto anatómico, capaz de representar o CG do corpo todo do nadador e, portanto, do seu estado energético, desenvolvido por mim próprio em 1993. Estes parâmetros, entretanto, foram relacionados com sucesso com o custo energético da locomoção, pelo autor no mesmo período.

Paralelamente, o André Costa havia-se entusiasmado com o desenvolvimento na Faculdade dos primeiros 
sistemas de processamento informático 2D de imagens de vídeo, em ordem à monitorização de coordenadas planares de pontos anatómicos relevantes. Recorria-se, então, ao velho AMIGA 2000, um dos primeiros computadores adquiridos pela Faculdade, por alturas de 1988, ao visual basic como linguagem de programação e aos equipamentos vídeo U-Matic de que se dispunha já nos "serviços de audiovisuais". Foi a partir de então que se tornou acessível o estudo aprofundado da cinemática segmentar e do CG de nadadores (DIGINAT) e de corredores e saltadores no Atletismo (DIGIAMIGA).

E foi também a partir desta iniciativa que foi possível persuadir o então presidente do Conselho Directivo, o Professor António Marques, a adquirir o primeiro equipamento laboratorial de Biomecânica que se tornou efectivamente operativo na Faculdade: o PEAK 5, da PEAK PERFORMANCE SYSTEMS, adquirido nos primeiros anos da década de 90 . O PEAK 5 instituiu-se, então, como o verdadeiro pretexto e a coluna vertebral do então criado Laboratório de Biomecânica, instalado numa divisão das instalações provisórias que ocupávamos na Reitoria da Universidade do Porto. Na altura dispúnhamos já de um par de electrogoniómetros, mas carecidos de interface analógico/digital que os pudesse transformar em instrumentos relevantes para os primeiros esboços de investigação científica. A cinemetria biomecânica a partir de imagiologia vídeo foi, portanto, o verdadeiro elemento precursor do actual Laboratório de Biomecânica e da respectiva prestação de serviços à comunidade desportiva. $\mathrm{E}$ foi também a causa indirecta da trágica morte do André Costa. Morte que o esperou num acidente onde desapareceram também o AMIGA 2000, o DIGIAMIGA e o DIGINAT e onde sobreviveu o vídeo PANASONIC AG7350 que ainda hoje opera como base do $P E A K 5$ e que tão relevantes serviços vem prestando aos estudantes de graduação e de pós-graduação nas aulas laboratoriais de Cinemetria Biomecânica.

Foi por estas razões que o nosso Laboratório recebeu o nome do Dr. André Costa, um homem que merecia partilhar connosco este momento solene de homenagem a dois outros homens que admirava profundamente: o meu orientador e o orientador dele; o físico e o anatomista; os homens que, connosco e com todas as boas vontades e competências que se reunis- sem no mesmo desiderato, nos haveriam de ajudar a fazer nascer uma nova Biomecânica na FCDEF-UP; uma biomecânica laboratorial que interfaceasse eficazmente a universidade e o atleta, a teoria e a práti$\mathrm{ca}$, e ajudasse a potenciar o valor intrínseco dos nossos desportistas. É que é exactamente isto que é a Biomecânica e a Biomecânica Desportiva em particular: uma disciplina da Biofísica, domínio da Física aplicada aos sistemas biológicos, de entre os quais sobressai a anatomia humana e a respectiva funcionalidade em contexto desportivo como expoentes máximos de complexidade e optimização; uma disciplina emergente da confluência de saberes da Física, da Biologia e do Desporto.

Estava formada a equipa ideal! Só lhe faltou oportunidade para entrar toda em campo de uma só vez. Mas ficou a intenção, restou a semente e sobrou a vontade de a fazer germinar. Assim parece estar a acontecer. Entre o início dos anos 90 e 1997 foram defendidas três teses de doutoramento em Biomecânica na FCDEF-UP. Para além da tese do Prof. José Luís de Castro Gonçalves, as duas restantes foram orientadas pelo Professor Ferreira da Silva (a minha e a do Doutor LUÍS ALBERTO BAPTISTA da UERJ). Uma outra ficou inconcluída. Não chegou a ser defendida, mas coube-me o privilégio, conjuntamente com os Professores José Maia e José Alberto Duarte, de a ter preparado para vir a público: foi o último legado do André Costa.

No mesmo período foram defendidas 5 teses de mestrado na área: uma relativa ao ciclo da marcha, uma outra que assumiu como objecto a chamada para o Salto em Comprimento em Atletismo, outra centrada nos efeitos da fadiga sobre a técnica em Natação, uma quarta relativa à cinemática dos saltos em Ginástica Rítmica Desportiva e, finalmente, uma outra em actividade física adaptada (avaliação postural). Foi ainda dado apoio a uma dúzia de monografias de Licenciatura, especialmente focadas nas áreas do Atletismo, Natação e Ginástica.

1997 foi o ano que marcou a mudança de responsabilidades no quadro da direcção do Laboratório de Biomecânica da Faculdade e da regência das disciplinas de licenciatura e de mestrado.

Das prioridades que defini com a assunção de funções como Coordenador do Gabinete de Biomecânica e como Coordenador do Laboratório de Biomecânica 
Dr. André Costa, entendidas de forma integrada, destaca-se, fundamentalmente, a efectiva implementação do Laboratório como espaço de leccionação, de investigação e de avaliação biomecânica, perspectivando a prestação de serviços à comunidade. Como já foi dito, o Laboratório de Biomecânica da FCDEF-UP era, ao tempo, virtualmente inexistente, dado que se encontrava dotado quase que exclusivamente do sistema PEAK 5 e de um par de goniómetros não interfaceados. Complementarmente, o Laboratório e o Gabinete contavam apenas com um staff interno de dois elementos, para além da persistente colaboração do Professor Ferreira da Silva, tendo o segundo destes (uma monitora) colaborado apenas um ano com a estrutura.

As linhas de força seleccionadas para o desenvolvimento desta Unidade foram as seguintes:

(i) aumento do número de sujeitos activos, nomeadamente conseguindo a contratação de um assistente e de um técnico, vinculando os estudantes em desenvolvimento de projectos (especialmente ao nível de doutoramento e de mestrado, mas também ao nível de licenciatura) e procurando o concurso voluntário de outros contributos relevantes, mormente em regime de parceria interinstitucional com outras faculdades;

(ii) diversificação das formações de origem dos agentes interventores no quotidiano do Laboratório, favorecendo a abertura de horizontes nos diferentes domínios de intervenção da unidade;

(iii) aumento do número de estudantes de pós-graduação envolvidos em projectos de Biomecânica, implicando a utilização e a vivência do Laboratório;

(iv) desenvolvimento de linhas de cooperação com outros laboratórios congéneres e instituições, promovendo a respectiva fertilização cruzada, seja no domínio das experiências e dos projectos, seja no domínio da formação dos agentes envolvidos e da leccionação;

(v) dotação de meios que tornassem o Laboratório efectivamente operante no domínio da investigação biomecânica e

(vi) efectiva potenciação da produção científica da unidade e da respectiva interacção com a comunidade científica.
Cinco anos e meio volvidos, o Laboratório e o Gabinete de Biomecânica contam hoje com o seguinte staff:

(i) um professor associado e uma assistente, ambos com formação básica em Ciências do Desporto;

(ii) um professor auxiliar convidado ao abrigo do $\mathrm{Art}^{\circ} 79^{\circ}$ do ECDU, físico;

(iii) um técnico de laboratório contratado a 50\%, licenciado em Engenharia Electrónica e Informática.

Para além destes elementos, temos o privilégio de continuarmos a contar com a colaboração do Professor Ferreira da Silva, nomeadamente através da orientação de projectos de investigação em curso. Em regime de parceria, colabora ainda com o grupo o Dr. João Carvalho, físico de formação e assistente da Faculdade de Engenharia da Universidade do Porto, que se tem revelado como um elemento decisivo da nova dinâmica do grupo.

O aumento de efectivos, a sua formação diversificada e a interacção com outras unidades similares, permitiram aumentar o capital crítico do conjunto, bem como o quadro de competências efectivas para a intervenção no domínio da investigação e desenvolvimento tecnológico em Biomecânica.

Foi entretanto defendida mais uma tese de doutoramento, também orientada pelo Prof. Ferreira da Silva, estando em curso mais 6 , uma delas também co-orientada pelo Professor Ferreira da Silva. Uma outra tese de doutoramento, no caso desenvolvida no Gabinete de Biologia, contou ainda com apoio instrumental e metodológico do Laboratório de Biomecânica para a realização de uma parte do estudo, nomeadamente no que concerne ao estudo da mobilidade das moscas Drosophilas Melanogaster contidas em caixas de diferentes dimensões.

Concomitantemente apoiamos o desenvolvimento de duas teses de mestrado da FCDEF da Universidade de Coimbra, nomeadamente de duas docentes da Universidade de Aveiro, tendo já sido concluídas com êxito 19 teses de mestrado, estando ainda $8 \mathrm{em}$ desenvolvimento, para além das 2 teses exteriores já referidas. Foi ainda dado apoio ao desenvolvimento de 14 monografias de Licenciatura, estando mais duas em curso. 
Estes trabalhos relevam do desenvolvimento de interfaces com outras unidades funcionais da Faculdade, nomeadamente com os Gabinetes de Ginástica, Futebol, Natação, Atletismo, Basquetebol, Andebol, Actividade Física Adaptada, Desporto de Recreação e Lazer, Biologia do Desporto e estendem-se por três dos quatros domínios fundamentais de intervenção da Biomecânica: cinemetria, dinamometria (dinâmica e estabilométrica) e electromiografia, valorizando-se a sua implicação simultânea, naturalmente sincronizada e cruzada, de tal forma que se possa perceber melhor toda a complexidade do funcionamento do sistema biomecânico: seja no domínio da produção de forças, seja no domínio do fluxo energético do corpo todo e na dinâmica inter-segmentar.

Os principais projectos de investigação desenvolvidos nesta nova fase da vida do Laboratório e do Gabinete de Biomecânica da FCDEF-UP afectaram-se a várias esferas, das quais destacamos apenas algumas, já que seria fastidiosa a sua enumeração exaustiva:

(i) a avaliação, modelação e optimização da chamada para o salto em comprimento, recorrendo à avaliação, entre outros parâmetros inovadores, da stiffness muscular por ultra-sonografia. Tratase do projecto de doutoramento do Mestre Filipe Conceição, desenvolvido em parceria com a Universidade de Desporto de Colónia, Alemanha e com o envolvimento imprescindível do Dr. João Carvalho, da FEUP;

(ii) o desenvolvimento de sistemas de bio-feedback para o ensino e treino da técnica de nadadores por velocimetria mecânica, que se consubstancia no núcleo central do projecto de doutoramento do Dr. António Barroso Lima;

(iii) a utilização de outros velocímetros, como por exemplo um radar, para o estudo de múltiplas variáveis, como a mudança de regulação da corrida de aproximação, em salto em comprimento, ou a velocidade da bola de futebol após remate (estudo desenvolvido em parceria com o Gabinete de Futebol da FCDEF-UP e com o Serviço de Oftalmologia do Hospital de S. João, nomeadamente através da colaboração do Dr. João Capão Filipe);

(iv) o estudo electrogoniométrico e electromiográfico de diferentes movimentos específicos em condi- ções de sobrecarga particular, incluindo estudos electromiográficos na água, seguindo a já tradicional linha de investigação acerca dos efeitos da fadiga na biomecânica do gesto desportivo;

(v) a caracterização podo-barométrica da marcha de diabéticos tipo II com níveis diferenciados de actividade física, em colaboração com a consulta de Pé Diabético do Hospital de S. João;

(vi) o estudo das repercussões no ciclo da marcha e na equilibração da utilização de mochilas escolares por alunos do ensino básico;

(vii) a avaliação da estabilidade do equilíbrio do idoso por estabilogrametria do centro de pressão;

(viii) a avaliação do sistema de categorização de deficiências em provas adaptadas de natação tendo por base a avaliação da força propulsiva por dinamometria directa na água;

(ix) repercussões cinemáticas e podobarométricas no ciclo da marcha implicadas por diferentes meniscopatias. Projecto desenvolvido em parceria com o Serviço de Ortopedia do Hospital Geral de Santo António;

(x) a avaliação, por dinâmica inversa, bi e tridimensional, das forças internas a que está sujeito o sistema biomecânico. Este projecto, liderado pela Mestre Filipa Sousa, impõe ainda o desenvolvimento de um dinamómetro por fibra óptica para avaliação in vivo de forças internas (através de implante cirúrgico), por forma a validar os cálculos desenvolvidos por dinâmica inversa.

Estes são apenas alguns dos projectos que já desenvolvemos, ou que temos entre mãos. Recentemente nasceu mais um, e mais uma vez com forte participação do Professor Ferreira da Silva, depois de concluído com êxito o doutoramento que orientou do Doutor Alberto Graziano, da Universidade Pedagógica do Maputo. Refiro-me ao estudo das alterações biomecânicas do ciclo da marcha observadas durante a gestação e o ulterior desenvolvimento de ortoteses específicas para o reforço da comodidade da gestante no quadro da sua actividade física regular. Trata-se do projecto de doutoramento do Mestre Manuel Rubim Santos, docente de Biomecânica da Escola Superior de Tecnologia da Saúde do Porto (curso de Fisioterapia), físico de formação graduada e pós-graduada a nível de mestrado 
e hoje doutorando co-orientado pelo Professor Ferreira da Silva e por mim próprio.

Para a implementação destes projectos, têm sido desenvolvidos pelo Laboratório diferentes meios electrónicos (em hardware ou software) específicos, como sejam, por exemplo:

(i) uma unidade de Avaliação Electromiográfica Bipolar (EMG) de oito canais com filtragem em hardware, que inclui uma versão específica (ainda experimental) para a monitorização EMG em ambiente aquático;

(ii) uma unidade de Sincronização Múltipla de Sinal analógico;

(iii) várias unidades específicas de sincronização de sistemas vídeo com equipamento de dinamometria;

(iv) várias rotinas de software em base MatLab para o tratamento e sincronização de sinal, seja electromiográfico, seja de pressão plantar, seja dinamométrico (impulsões sincronizadas com EMG, ou no domínio particular da estabilogrametria nas componentes de regulação postural -trembling e rambling);

(v) rotinas de software em base MatLab para a modelação e simulação de variáveis dinâmicas da impulsão;

(vi) meios de adaptação de plataformas de força a diferentes ambientes, desde logo ao próprio ambiente laboratorial, mas também, e em especial, à piscina, por forma a permitir a avaliação dinamométrica e cinemática integradas das partidas para natação pura desportiva;

(vii) meios para a calibração cinemétrica de imagens de vídeo de diferentes dimensões;

(viii) um velocímetro por cabo para o registo "on line" das flutuações intracíclicas da velocidade do nadador;

(ix) rotinas de software em base MatLab para modelação do sinal do velocímetro mecânico;

(x) rotinas para o processamento da cinemática fascicular muscular obtida por ultra-sonografia, em ordem ao cálculo da rigidez muscular.

O desenvolvimento de linhas de cooperação com outros laboratórios similares vem sendo incentivado, quer no domínio da leccionação, quer no da investi- gação e formação, e constitui um auxiliar precioso de todo este processo evolutivo. Destacam-se, neste contexto, as interacções com unidades brasileiras, nomeadamente o Laboratório de Biomecânica da Escola de Educação Física da Universidade de São Paulo, dirigido pelo Professor Alberto Carlos Amadio, e o Laboratório de Pesquisa do Exercício da Escola de Educação Física da Universidade Federal do Rio Grande do Sul, dirigido pelo Professor António Carlos Guimarães.

Qualquer destas unidades, e dos respectivos directores, coopera com a FCDEF-UP através da participação no esforço de leccionação em cursos de pós-graduação, nomeadamente no Curso de Mestrado em Ciência do Desporto na área de especialização de Treino de Alto Rendimento, através dos Seminários de Biomecânica e de Avaliação Electromiográfica. A cooperação, porém, estende-se à realização de estágios de investigação de elementos do nosso Laboratório, de onde vem emergindo um já apreciável número de publicações internacionais conjuntas, mormente pela mão da Mestre Filipa Sousa. Da última das unidades referidas recebemos, em contrapartida, a visita, como estagiário, do Professor Jefferson Loss. No Brasil estabeleceram-se também contactos relevantes, que permitiram a realização de estágios por parte do staff do Laboratório, com o Laboratório de Biomecânica da Escola de Educação Física, Fisioterapia e Desportos da Universidade do Estado de Santa Catarina, dirigido pelo Professor Aluísio Ávila. Mas, apesar das excelentes relações com o Brasil, que se pode dizer terem culminado, recentemente, com nossa participação no IX Congresso Brasileiro de Biomecânica (2001), foi julgado conveniente desenvolver também importantes linhas de cooperação com a Europa.

Assim, estudantes de doutoramento do Laboratório e, simultaneamente, docentes da FCDEF-UP, realizaram estágios de investigação nos seguintes laboratórios: (i) no Laboratório de Biomecânica da Faculdade de Ciências do Desporto da Universidade da Extremadura, Espanha, dirigido pelo Professor Kostas Gianikellis, Chairman do Congresso 2002 da International Society of Biomechanics in Sports (ISBS) e (ii) no Laboratório de Biomecânica da Universidade de Desporto de Colónia, Alemanha, dirigido pelo Professor Peter Brüggemann, de onde recebemos já, 
em estágio, o Professor Harald Boehm. Desta linha de cooperação vem emergindo um conjunto muito relevante de novas experiências, competências e resultados, nomeadamente os que decorrem dos trabalhos desenvolvidos pelo doutorando Filipe Conceição no domínio da avaliação da rigidez muscular por ultra-sonografia. Para além das colaborações com laboratórios estrangeiros, alargou-se ainda o quadro de cooperação com o Laboratório de Biomecânica da Faculdade de Motricidade Humana da Universidade Técnica de Lisboa, dirigido pelo Professor João Abrantes, no qual se realizou a recolha de dados para um dos projectos de investigação em curso.

Ainda no que concerne à cooperação com outras instituições, cabe também referir as recentes parcerias, ainda que informais, desenvolvidas com a Escola Superior de Tecnologia da Saúde do Porto (curso de Fisioterapia), com a Consulta de Pé Diabético do Hospital de S. João e com os serviços de Ortopedia e de Medicina Física e Reabilitação do Hospital Geral de Sto. António. Desta última, realce para o facto de ter resultado num prémio de investigação atribuído pelo Secretariado Nacional de Reabilitação.

Uma outra linha fundamental de desenvolvimento do Laboratório e do Gabinete passou pela reperspectivação da docência da Biomecânica na FCDEF-UP, procurando-se valorizar a formação laboratorial dos estudantes. O reforço da componente laboratorial do ensino foi viabilizada pelas decisões, em tempo, dos Conselhos Pedagógico e Científico da FCDEF-UP, concretamente permitindo o desdobramento das turmas práticas em dois grupos cada, tornando exequíveis as aulas laboratoriais em efectivo contacto estreito com os materiais e equipamentos.

Esta opção pedagógica parece ter rendido os dividendos esperados, traduzidos, principalmente, numa acentuada redução do insucesso escolar, num aumento do número de estudantes de pós-graduação a procurar o Laboratório e, sobretudo, numa clara redução do absentismo às aulas pelos estudantes de graduação e pós-graduação.

Enfim, todo este percurso rendeu, por certo, também dividendos apreciáveis na comunidade escolar e na mais vasta comunidade académica e científica da nossa universidade, do país e de outras nações. Permitiu-nos consolidar parcerias e desenvolver novos projectos de cooperação. Permitiu-nos ganhar o respeito dos nossos pares, traduzido na integração de conselhos científicos e editoriais de várias organizações e publicações internacionais com avaliação entre pares e permitiu-nos ganhar recentemente a organização, no Porto em 2006, do World Congress on Biomechanics and Medicine in Swimming.

Todo este caminho tem a marca indelével da presença do Professor Ferreira da Silva. E se é certo que ganhou já uma quantidade de movimento suficiente para dificilmente ser detida, esta dinâmica sofrerá certamente com a menor disponibilidade futura do Professor. Porém, atrevemo-nos a manter a esperança de podermos sempre contar com o seu apoio, o seu conselho avisado, a sua experiência e, sobretudo, a sua amizade, pelo menos enquanto que a paciência lho permitir.

Muito obrigado por nos ter feito chegar aqui com a descrição própria dos desprendidos, com a sobriedade dos grandes, com a elevação dos cultos e com a mestria dos sábios... mas sobretudo com a amizade dos verdadeiros! BEM HAJA! 